\title{
PENERAPAN MODEL WATERFALL DALAM SISTEM UJIAN SEKOLAH BERBASIS WEB PADA SMK WIRA BUANA I BOGOR
}

\author{
Jayusman'; Sri Wasiyanti² $^{2}$ \\ ${ }^{1}$ Sistem Informasi \\ STMIK Nusa Mandiri \\ www.nusamandiri.ac.id \\ zayus29@gmail.com \\ ${ }^{2}$ Sistem Informasi Akuntansi \\ Universitas Bina Sarana Informatika \\ www.bsi.ac.id \\ sri.siw@bsi.ac.id
}

\begin{abstract}
Examination and repetition of activities such as midterm tests, semester tests and class increase examinations at SMK Wira Buana 1 Bogor are still manual, namely using paper, this is felt to be less effective because it takes a lot of costs, time, place and personnel in its implementation and still exists cheating students in carrying out the exam. In addition, the development of information technology and systems in the world of education is increasing, one example is the Computer Based National Examination (UNBK) also called the Computer Based Test (CBT), which is a system of implementing national examinations using computers as a test medium. This is the background of the author to make a web-based school exam information system there is SMK Wira Buana 1 Bogor. The method used in designing this webbased examination system is the waterfall method which is expected to be one of the breakthroughs in the running of the School Examination, both the Mid-Semester Examination and the Semester Final Examination which can reduce the operational costs of activities. The School Examination Information System becomes a medium for students to practice computer-based exams that can be accessed by all students of Bogor Wira Buana 1 Vocational School so that they can improve readiness and familiarize students in facing Computer-Based National Exams and provide convenience for schools in conducting examinations and providing speed in get the test result score.

Keywords: School examinations, Waterfall method, web based.
\end{abstract}

Intisari- Pelaksanaan kegiatan ujian dan ulangan seperti ulangan tengah semester, ulangan semester dan ujian kenaikan kelas di SMK Wira Buana 1 Bogor masih manual yaitu menggunakan kertas, hal ini dirasa masih kurang efektif karena banyak memakan biaya, waktu, tempat dan personil dalam pelaksanaannya serta masih terdapat tindak kecurangan siswa dalam melaksanakan ujian. Selain itu, perkembangan teknologi dan sistem informasi didalam dunia pendidikan semakin meningkat, salah satu contohnya adalah Ujian Nasional Berbasis Komputer (UNBK) disebut juga Computer Based Test (CBT) yaitu sistem pelaksanaan ujian nasional dengan menggunakan komputer sebagai media ujiannya. Inilah yang melatar belakangi penulis untuk membuat sistem informasi ujian sekolah berbasis web ada SMK Wira Buana 1 Bogor. Metode yang digunakan dalam merancang sistem ujian berbasis web ini adalah metode waterfall yang diharapkan akan menjadi salah satu terobosan dalam penyelanggaraan Ujian Sekolah baik Ujian Tengah Semester dan Ujian Akhir Semester yang mampu menekan biaya operasional kegiatan. Sistem Informasi Ujian Sekolah menjadi media bagi siswa untuk latihan ujian berbasis komputer yang dapat diakses oleh seluruh siswa SMK Wira Buana 1 Bogor sehingga dapat meningkatkan kesiapan dan membiasakan siswa dalam menghadapi Ujian Nasional Berbasis Komputer serta memberikan kemudahan bagi pihak sekolah dalam pelaksanaan ujian dan memberikan kecepatan dalam memperoleh nilai hasil ujian.

Kata kunci: Ujian sekolah, Metode Waterfall, berbasis web..

\section{PENDAHULUAN}

Perkembangan teknologi dan sistem informasi didalam dunia pendidikan semakin meningkat, salah satu contohnya adalah Ujian Nasional Berbasis Komputer (UNBK) disebut juga Computer Based Test (CBT) yaitu sistem pelaksanaan ujian nasional dengan menggunakan komputer sebagai media ujiannya. 
Sebelum pelaksanaan Ujian Nasional Berbasis Komputer tahap akhir diadakan ujian percobaan sebanyak 2 kali sebagai pelatihan siswa dalam menghadapi ujian, hal ini dirasa masih kurang cukup (Firdaus \& Dewi, 2016) untuk membiasakan siswa menghadapi ujian nasional berbasis komputer karena dalam ulangan atau ujian yang dilaksanakan di sekolah masih menggunakan kertas atau berbasis Paper Based Test (PBT)(Sudaryati, 2016).

Pembuatan Sistem Ujian Online STMIK POLITEKNIK PalComTech ini dibuat menggunakan bahasa pemrogaman yaitu PHP dan database MySQL. Sistem ini dapat membantu proses ujian STMIK-POLITEKNIK PalComTech menjadi lebih efisien, baik itu kuis, Ujian Tengah Semester, ataupun di Ujian Akhir Semester, sesuai dengan tujuan STMIK - POLITEKNIK yang akan menerapkan sistem pendidikan abad $21 \mathrm{Hal}$ ini dapat meningkatkan kualitas pendidikan STMIKPOLITEKNIK PalComTech, demi tercapainya ujian yang adil dan bersifat objektif(Gunawan, 2015). Dalam penelitian lainnya disebutkan bahwa Pelaksanaan Try Out Ujian Nasional di sekolah juga masih ditemukan beberapa permasalahan. Yaitu diantaranya pelaksanaan try out ujian yang masih menggunakan kertas sebagai bahan soal dan kertas jawaban sehingga menyita waktu dan biaya dalam penggandaan soal dan kertas jawaban. Adanya kemungkinan terjadinya kertas jawaban siswa yang rusak/hilang karena kesalahan manusia(Reni Hendrawati \& Fatkhudin, 2015). Serta pengoreksian yang masih memerlukan waktu beberapa hari untuk diketahui hasilnya. Disamping itu biaya bimbingan belajar yang mahal membuat banyak siswa tidak mengikuti bimbingan belajar di luar sekolah (nonformal) (Reni Hendrawati, 2015).

Saat ini sistem ujian yang dijalankan pada STMIK Bina Sarana Global masih manual, sehingga memerlukan waktu dan biaya yang tidak sedikit. Dalam pelaksanaannya sistem manual masih terdapat beberapa kendala seperti sering terjadi kekurangan lembar soal ujian, membutuhkan banyak pengawas sedangkan SDM belum memenuhi, dosen sering terlambat mengirimkan soal ujian kepada akademik sedangkan soal ujian harus diperiksa terlebih dulu untuk menyesuaikan dengan standar soal(Julianti \& Silalahi, 2015). Dengan menggunakan sistem ujian online berbasis web ini, membuat pekerjaan dalam mengadakan ujian UTS/UAS, memberi penilaian dan pelaporan nilai bisa lebih mudah dan cepat dari segi waktu dan biaya(Julianti \& Silalahi, 2015).

Pelaksanaan kegiatan ujian dan ulangan seperti ulangan tengah semester, ulangan semester dan ujian kenaikan kelas di SMK Wira
Buana 1 Bogor yang masih manual yaitu menggunakan kertas, hal ini dirasa masih kurang efektif karena banyak memakan biaya(Rahardja \& Handayani, 2016), waktu, tempat dan personil dalam pelaksanaannya serta masih terdapat (Murdiansyah, Sudarma, \& Nurkholis, 2017). Biaya dalam hal ini adalah dana yang dikeluarkan untuk menyediakan dokumen-dokumen ujian seperti fotokopi lembar soal, fotokopi lembar jawaban serta biaya koreksi hasil lembar jawaban siswa. Waktu dalam hal ini adalah proses penggandaan soal dan lembar jawaban siswa, proses koreksi lembar jawaban siswa oleh guru, proses-proses ini membutuhkan waktu cukup lama dalam pengerjaannya sehingga hasil dari ujian inipun juga membutuhkan waktu yang lama pula (Suryana, 2015). Kecurangan yang dimaksud dalam hal ini adalah siswa masih mencontek dan berbagi jawaban dengan temannya karena urutan soal ujian sama (Sulistiyono, Suyata, \& Rahayu, 2016). Oleh karena itu, untuk memudahkan pihak sekolah dan siswa dalam pelaksanaan ujian maka dirancanglah sistem ujian online di SMK Wira Buana 1 Bogor dengan metode waterfall.

\section{BAHAN DAN METODE}

Dalam penelitian ini, penulis mengumpulkan data melalui metode:

A. Pengamatan Langsung (Observasi)

Penulis melakukan pengamatan secara langsung dengan melihat arsip dan dokumentasi kegiatan ulangan dan ujian seperti lembar soal ulangan, lembar jawaban dan lembar penilaian siswa yang ada pada SMK Wira Buana 1 Bogor sebagai sumber data yang dijadikan acuan dalam pembuatan sistem ini.

B. Wawancara

Penulis melalui wawancara dengan pihak pihak terkait di SMK Wira Buana 1, seperti wawancara dengan kepala sekolah, Wakil Bidang Kurikulum, Guru, dan pihak terkait lainnya yang mempunyai kompetensi dengan sekolah tersebut.

C. Studi Pustaka

Penulis mengumpulkan informasi yang diperlukan dengan membaca buku-buku, jurnal mengenai sistem informasi ujian berbasis website.

Metode pengembangan yang digunakan adalah waterfall. Model ini memberikan pendekatan - pendekatan sistematis dan berurutan bagi pengembangan sistem. Proses mengembangkan atau mengubah suatu sistem perangkat lunak dengan menggunakan model model dan metodologi yang digunakan orang 
untuk mengembangkan sistem - sistem perangkat lunak sebelumnya(Rosa Ariani Sukamto, 2013) Tahapan dari metode waterfall adalah sebagai berikut:

\section{A. Analisa Kebutuhan Sistem}

Pada Sistem Informasi Ujian Berbasis Web, siswa SMK Wira Buana 1 - Bogor sebagai pengguna dapat mengakses menggunakan nomor induk siswa sebagai user id dan tanggal lahir sebagai password dan memilih program keahlian. Setelah login siswa dapat mengikuti ujian sesuai jadwal, selanjutnya siswa dapat melihat hasil ujian sehingga dapat dijadikan sebagai acuan kemampuan siswa dalam menguasai materi yang diajarkan. Untuk menunjang sistem ini maka dibutuhkan data - data siswa sebagai pengguna dalam sistem ini, penulis mendapatkan data siswa berupa softcopy dalam bentuk file Microsoft Office Excel. Selain data siswa diperlukan juga data guru yang akan diberikan akses sebagai admin agar dapat melakukan pembuatan soal-soal ujian, penentuan batas nilai kelulusan atau kriteria ketuntasan minimal (KKM). Penulis mendapatkan data guru berupa softcopy dalam bentuk file Microsoft Office Excel. Guru dapat mengakses sistem dengan menggunakan nomor induk karyawan (NIK) sebagai user id dan tanggal lahir sebagai password, khusus untuk guru dan admin password dapat diubah sewaktu-waktu demi keamanan sistem ujian berbasis web ini.

\section{B. Desain}

Pada tahap ini, penulis melakukan perancangan sistem informasi ujian berbasis web meliputi desain database menggunakan ERD, rancangan user interface menggunakan Microsoft Visio, dan software architecture menggunakan Unified Modelling Language (UML).

\section{Code Generation}

Untuk mendukung pembuatan sistem ini penulis menggunakan bahasa pemograman PHP dengan pemrograman berbasis objek, Hyperlink Text Markup Languange (HTML), Database Management System (DBMS) menggunakan MySQL dengan Xampp.

\section{Testing}

Penulis melakukan test pada sistem informasi ujian berbasis web dengan menggunakan metode blackbox testing yang bertujuan untuk menemukan dan menimimalisir kesalahan pengguna serta mendemonstrasikan fungsi sistem. Black box testing berfokus pada kebutuhan fungsional pada software, berdasarkan pada spesifikasi kebutuhan dari software.

\section{E. Support}

Dalam pembuatan sistem informasi ujian berbasis web ini penulis menggunakan sistem operasi Windows 8 dan membutuhkan software pendukung seperti Sublime Text dan Macromedia Dreamweaver 8 dalam penulisan script program, Web Server Apache 2.4.17 dan Mysql 5.4 sebagai media penyimpan database, browser menggunakan Google Chrome dan Mozilla Firefox untuk mengakses sistem ini. Untuk perangkat keras (hardware) yang digunakan yaitu Notebook Lenovo Thinkpad L412 dengan sepesifikasi processor Intel Core i3, RAM 2 GB, Harddisk 500 GB.

\section{HASIL DAN PEMBAHASAN}

\section{A. Analisa Kebutuhan Sistem}

Berikut kebutuhan sistem informasi ujian sekolah berbasis web di SMK Wira Buana 1 Bogor: Halaman user atau siswa:

A1. User dapat login menggunakan nomor induk siswa sebagai userid dan tanggal lahir sebagai password dengan format (yyyy-mmdd),

A2. User dapat melihat dan mencetak jadwal ujian / KRS,

A3. User dapat mengikuti ujian sesuai jadwal ujian,

A4. User dapat melihat dan mencetak detail hasil ujian setiap mata pelajaran,

A5. User dapat melihat dan mencetak kartu hasil ujian / KHS,

Halaman Guru :

B1. Guru dapat login menggunakan nomor induk pegawai (NIP) sebagai userid tanggal lahir sebagai password standar dengan format (yyyy-mm-dd),

B2. Guru dapat melihat jadwal ujian,

B3. Guru dapat melihat hasil ujian siswa sesuai mata pelajaran yang diampu,

B4. Guru dapat melihat profile dan update password.

Halaman Admin :

C1. Admin dalam sistem ini adalah Staff Tata Usaha, admin dapat login username dan password yang dapat ditentukan sendiri.

C2. Admin dapat mengelola data admin,

C3. Admin dapat mengelola data guru,

C4. Admin dapat mengelola data siswa,

C5. Admin dapat mengelola data kelas dan program studi,

C6. Admin dapat mengelola data mata pelajaran,

C7. Admin dapat melihat data soal-soal ujian,

C8. Admin dapat melakukan pengaturan jadwal ujian, 
C9. Admin dapat melihat dan update data pribadi / profil serta password.

\section{B. Desain}

Pada tahap ini, penulis menggunakan Unified Modelling Language (UML).

A. Tahap Analisa

Sistem informasi ujian sekolah berbasis web adalah sistem ulangan / ujian sekolah secara online dimana siswa dapat melakukan ujian menggunakan komputer sebagai media ujian tidak lagi menggunakan media kertas sebagai lembar soal dan lembar jawaban sehingga tidak ada lagi biaya penggandaan soal dan lembar jawaban. Guru tidak perlu lagi mengoreksi lembar jawaban siswa karena jawaban siswa akan secara otomatis dikoreksi oleh sistem, guru hanya membuat soal soal ujian dan menentukan jawaban yang benar dari setiap soal, wali kelas tidak perlu lagi mengerjakan rekapitulasi dan membuat Kartu Hasil Semester (KHS) karena KHS dibuat secara otomatis oleh sistem, KHS merupakan hasil akhir yang dicapai dari sistem ini yang dapat dilihat dan dicetak oleh siswa. Berikut kebutuhan sistem informasi ujian sekolah berbasis web.

Halaman user atau siswa:

A6. User dapat login menggunakan nomor induk siswa sebagai userid dan tanggal lahir sebagai password dengan format (yyyy-mmdd),

A7. User dapat melihat dan mencetak jadwal ujian / KRS,

A8. User dapat mengikuti ujian sesuai jadwal ujian,

A9. User dapat melihat dan mencetak detail hasil ujian setiap mata pelajaran,

A10. User dapat melihat dan mencetak kartu hasil ujian / KHS,

Halaman Guru :

B5. Guru dapat login menggunakan nomor induk pegawai (NIP) sebagai userid tanggal lahir sebagai password standar dengan format (yyyy-mm-dd),

B6. Guru dapat melihat jadwal ujian,

B7. Guru dapat melihat hasil ujian siswa sesuai mata pelajaran yang diampu,

B8. Guru dapat melihat profile dan update password.

Halaman Admin :

C10. Admin dalam sistem ini adalah Staff Tata Usaha, admin dapat login username dan password yang dapat ditentukan sendiri.

C11. Admin dapat mengelola data admin,

C12. Admin dapat mengelola data guru,

C13. Admin dapat mengelola data siswa,
C14. Admin dapat mengelola data kelas dan program studi,

C15. Admin dapat mengelola data mata pelajaran,

C16. Admin dapat melihat data soal-soal ujian,

C17. Admin dapat melakukan pengaturan jadwal ujian,

C18. Admin dapat melihat dan update data pribadi / profil serta password.

\section{Usecase Diagram User}

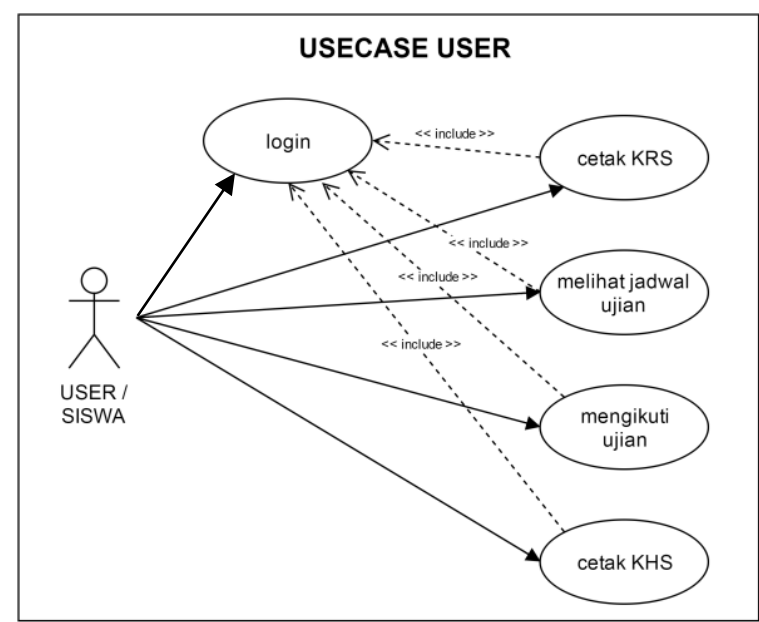

Sumber:(Jayusman \& Wasiyanti, 2018)

Gambar 1. Usecase Diagram User

Gambar 1 menunjukkan bahwa user/siswa dapat melakukan login sesuai dengan username dan password masing-masing, kemudian dapat mencetak KRS, melihat jadwal ujian, melakukan

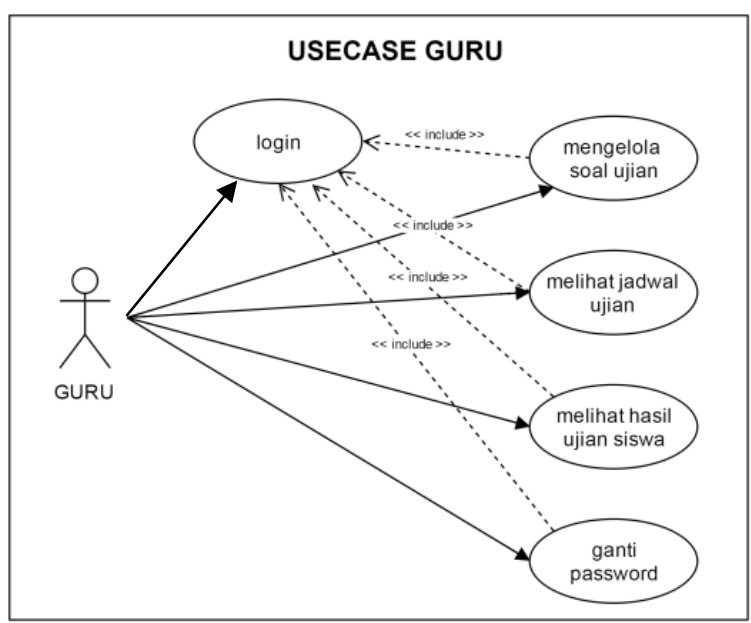

ujian dan cetak hasil ujian.

Sumber: (Jayusman \& Wasiyanti, 2018)

Gambar 2. Usecase Diagram Guru

Gambar 2 menunjukkan bahwa guru dapat melakukan login sesuai dengan username dan password masing-masing, kemudian dapat mengelola soal ujian, melihat jadwal ujian, melihat 
hasil ujian dan dapat melakukan penggantian password.

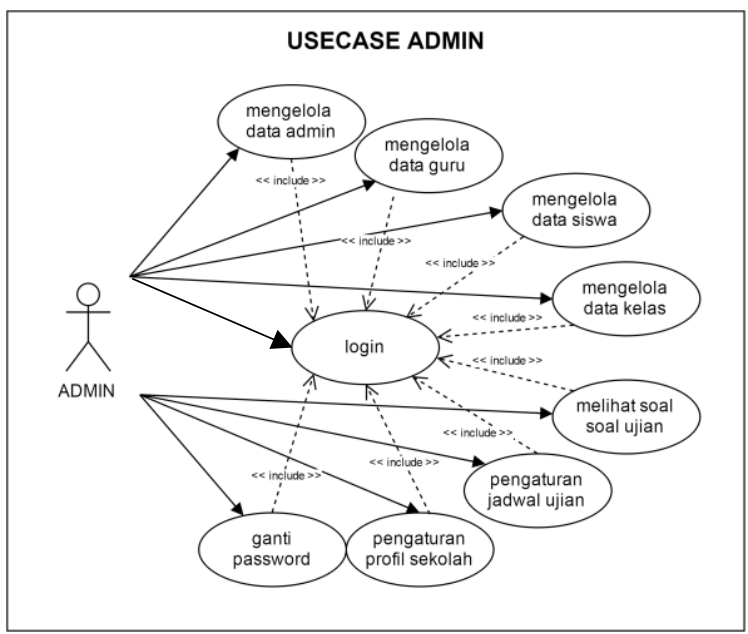

Sumber: (Jayusman \& Wasiyanti, 2018)

Gambar 3. Usecase Diagram Admin

Gambar 3 menunjukkan bahwa admin dapat melakukan login sesuai dengan username dan password masing-masing, kemudian dapat mengelola data admin, mengelola data guru, data siswa, data kelas, melihat soal ujian, pengaturan jadwal ujian, pengaturan profil sekolah dan dapat melakukan penggantian password.

\section{Activity Diagram}

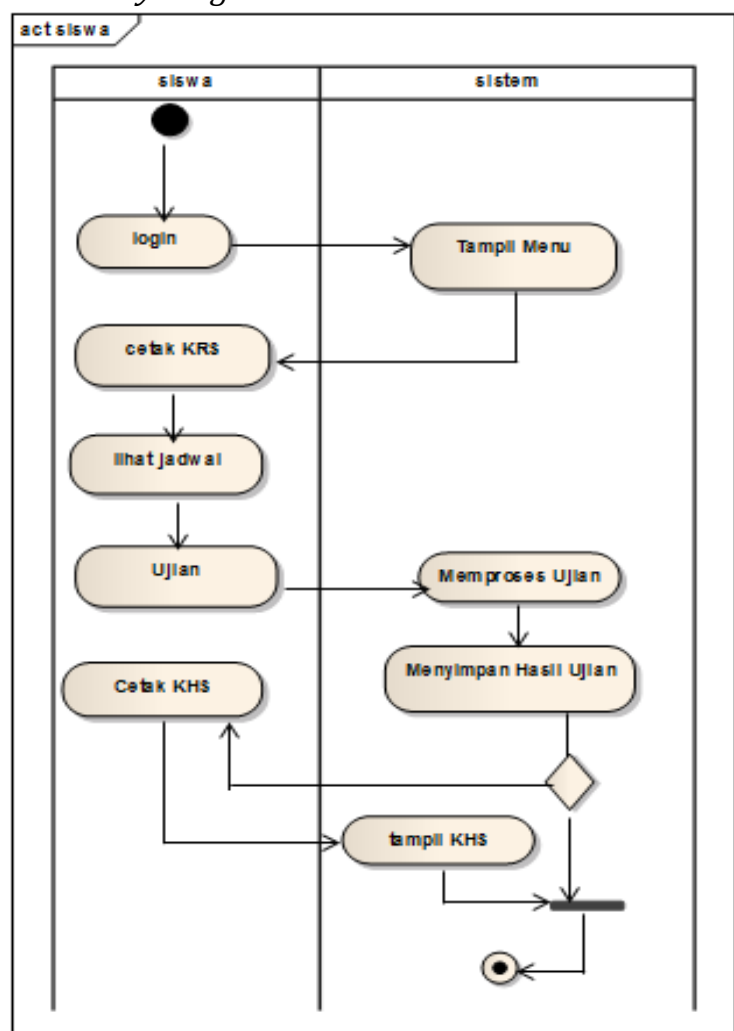

Sumber: (Jayusman \& Wasiyanti, 2018)

Gambar 4. Activity Diagram Siswa
Gambar 4 menunjukan aktifitas yang dapat dilakukan oleh siswa dalam sistem ujian berbasis web.

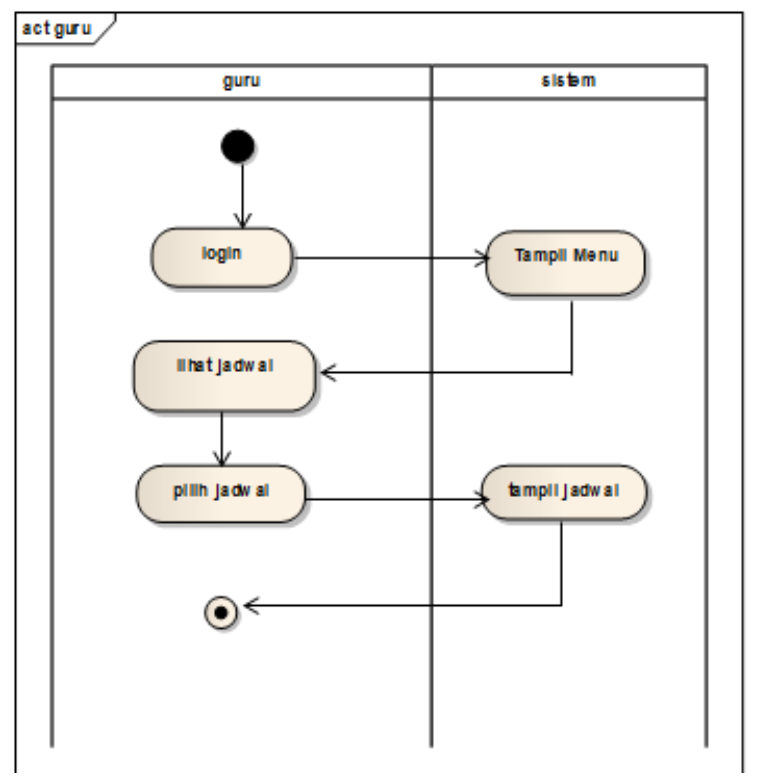

Sumber: (Jayusman \& Wasiyanti, 2018)

Gambar 5. Activity Diagram Siswa

Gambar 5 menunjukan aktifitas yang dapat dilakukan oleh guru dalam sistem ujian berbasis web.

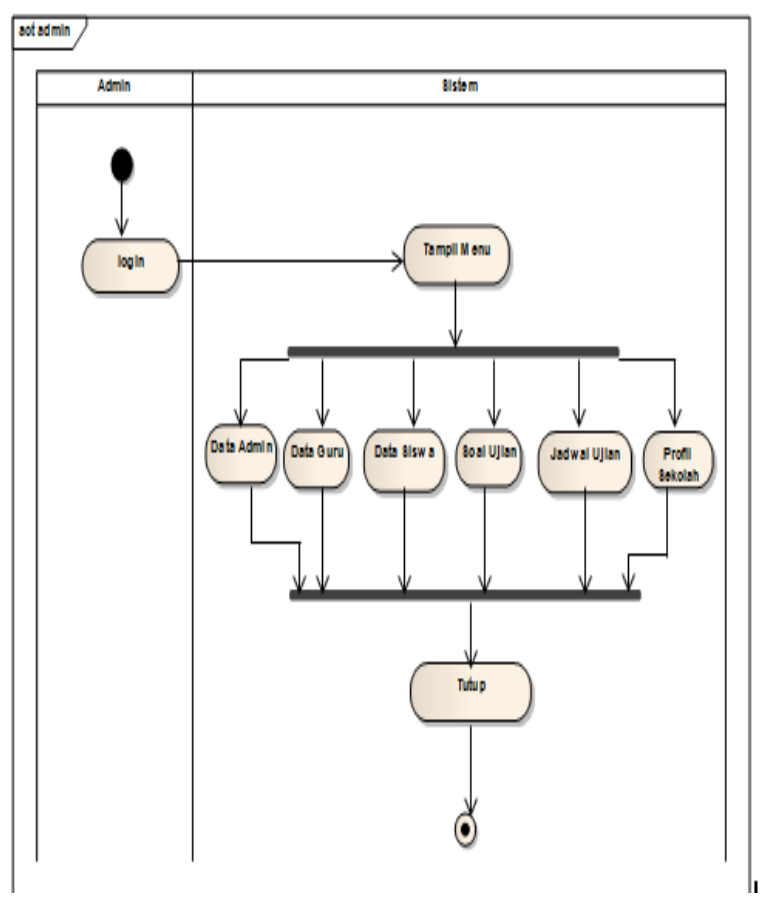

Sumber:(Jayusman \& Wasiyanti, 2018)

Gambar 6. Activity Diagram Siswa

Gambar 6 menunjukan aktifitas yang dapat dilakukan oleh admin dalam sistem ujian berbasis web. 
3. Entity Relationship Diagram(ERD)

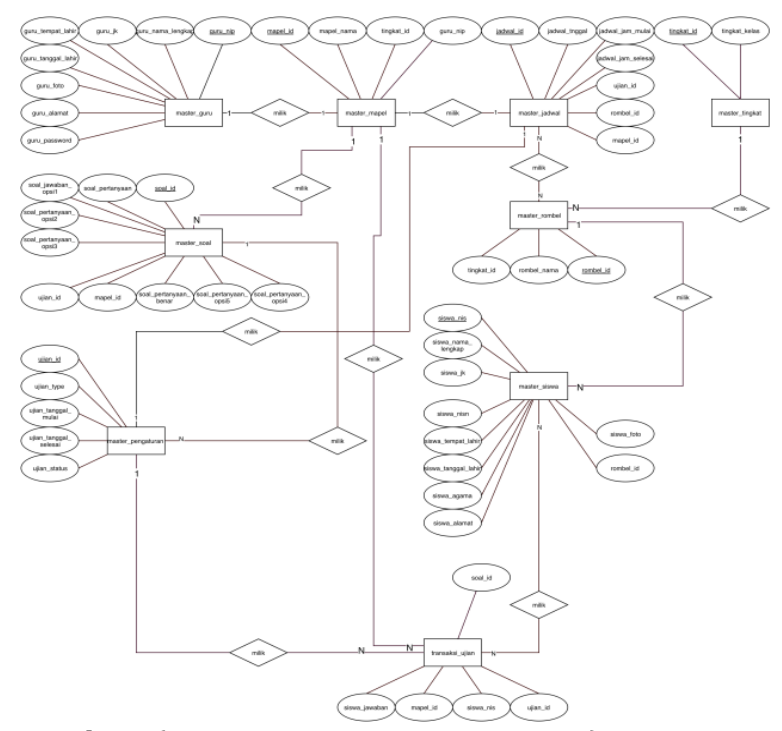

Sumber: (Jayusman \& Wasiyanti, 2018)

Gambar 7. Entity Relationship Diagram(ERD)

Gambar 7 menunjukan entitas, atribut dari masing-masing entitas dan relasi antar entitas dalam sistem ujian berbasis web.

\section{Deployment Diagram}

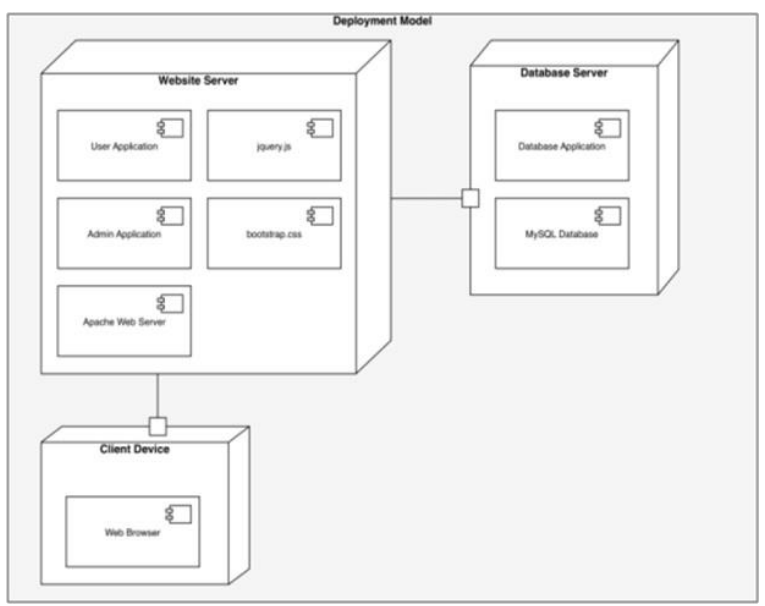

Sumber:(Jayusman \& Wasiyanti, 2018)

Gambar 8. Deployment Diagram

Gambar 8 menunjukan gambaran bagaimana sistem secara fisik akan terlihat, sistem diwakili oleh node-node, dimana setiap node diwakili oleh bentuk kubus, garis menghubungkan kubus merupakan gambaran hubungan antar node.

\section{Code Generation}

Berikut ini adalah kode program dari class ujian:

$<? p h p$

session_start(); class ujian \{

// properti

private \$dbHost = "localhost";

private $\$$ dbUser = "root";

private $\$$ dbPass = "'";

private \$dbName = "ujianonline_wb1";

function connectMySQLO

\{

mysql_connect(\$this->dbHost, \$this->dbUser,

\$this->dbPass);

mysql_select_db(\$this->dbName) or

die("Database tidak ada!");

\}

function tampilJadwal()

\{

$\$ q u e r y=$ mysql_query $\left(" S E L E C T{ }^{*}\right.$ FROM

master_jadwal

where tingkat_id= \$_SESSION[tingkat_id];");

while (\$row = mysql_fetch_array $(\$ q u e r y)$ ) \$jadwal[] = \$row;

\} return \$jadwal;

function tampilMapel(\$id)

\{

$\$ q u e r y=$ mysq__query $(" S E L E C T$ * FROM

master_mapel

where mapel_id = '\$id'; ");

while (\$row = mysql_fetch_array (\$query))

\$mapel[ $=$ \$row;

\} return \$mapel;

\section{function tampilSoal(\$id,\$kegiatan)}

\{

$\$ q u e r y=$ mysql_query $(" S E L E C T$ * FROM

master_soal where

mapel_id = '\$id' and ujian_id='\$kegiatan' ORDER

BY rand() limit 1; ");

while (\$row = mysq__fetch_array (\$query))

$\$$ soal []$=\$$ row;

return \$soal;

\}

function

tampilSoalJawaban(\$id,\$kegiatan,\$pelajaran)

\{

$\$ q u e r y=$ mysq__query $(" S E L E C T$ * FROM

master_soal where

soal_id = '\$id' and mapel_id='\$pelajaran' and

ujian_id='\$kegiatan'; ");

while (\$row = mysq__fetch_array (\$query)

$\$$ soal []$=\$$ row;

\} 
function

tampilJawaban(\$kegiatan,\$siswa,\$pelajaran)

\section{\{}

\$query = mysq_query ("SELECT * FROM

transaksi_ujian where ujian_id='\$kegiatan' and

siswa_nis='\$siswa' and mapel_id = '\$pelajaran'; "); while (\$row = mysqL_fetch_array $(\$ q u e r y))$ \$jawaban [] = \$row;

\} return \$jawaban;

\section{function}

simpanJawaban(\$ujian_id,\$siswa_nis,\$mapel_id, \$soal_id, \$siswa_jawaban)

\{

\$query = "INSERT INTO

transaksi_ujian(ujian_id,siswa_nis,mapel_id,

soal_id,siswa_jawaban) VALUES

('\$ujian_id','\$siswa_nis', '\$mapel_id', '\$soal_id',

'\$siswa_jawaban')"; \}

\$hasil = mysq__query(\$query);

\section{function hitungJawaban(\$type,\$siswa,\$pelajaran)}

\{

$\$ z=m y s q$ L_query("select $*$ from transaksi_ujian where ujian_id='\$type'

and siswa_nis='\$siswa' and

mapel_id='\$pelajaran' ");

\$jumlahdata=mysqI_num_rows $(\$ z)$;

\}\}

return \$jumlahdata;

$\$ d b=$ new ujian ();

$\$ d b$->connectMySQL();

?>

\section{Testing}

Hasil dari pengujian yang telah dilakukan adalah sebagai berikut:

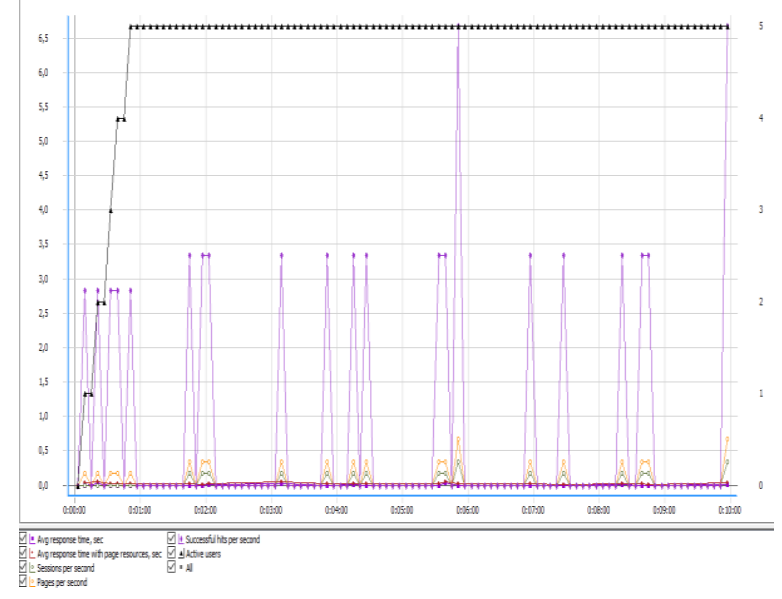

Sumber: (Jayusman \& Wasiyanti, 2018)

Gambar 9. Pengujian web menggunakan WAPT
Gambar 9 menunjukkan gambaran dari hasil pengujian yang telah dilakukan, dimana:

\section{Pengujian performa data:}

a. succesfull pages 41

b. succesfull hits 445

c. succesfull session 18

d.

\section{pengujian penggunaan bandwith:}

a. kecepatan pengiriman: $2.16 \mathrm{~KB} /$ second

$b$. kecepatan penerimaan: $206 \mathrm{~KB} /$ second

\section{KESIMPULAN}

Dari proses dan hasil penelitian Sistem Informasi Ujian Sekolah Berbasis Web pada SMK Wira Buana 1 ini, maka dapat diambil kesimpulan bahwa tersedianya wadah atau media bagi siswa untuk latihan ujian berbasis komputer yang dapat diakses oleh siswa SMK Wira Buana 1 Bogor, meningkatkan kesiapan dan membiasakan siswa dalam menghadapi Ujian Nasional Berbasis Komputer dan memberikan kemudahan bagi pihak sekolah dalam pelaksanaan ujian dan memberikan kecepatan dalam memperoleh nilai hasil ujian.

\section{REFERENSI}

Firdaus, F. F., \& Dewi, A. (2016). EVALUASI KUALITAS PELAYANAN TERHADAP KEPUASAN PASIEN RAWAT JALAN PESERTA BPJS DI RSUD PANEMBAHAN SENOPATI BANTUL.

Gunawan, R. (2015). SISTEM UJIAN ONLINE PADA STMIK-POLITEKNIK PALCOMTECH PALEMBANG, 5(2), 133-153.

Jayusman, J., \& Wasiyanti, S. (2018). Laporan Akhir Penelitian Mandiri. Jakarta.

Julianti, M. R., \& Silalahi, P. (2015). Perancangan Aplikasi Ujian Online Berbasis Web Study Kasus di STMIK Bina Sarana Global. Jurnal Sisfotek Global, 5(2), 91-94. Retrieved from https://stmikglobal.ac.id/journal/index.php /sisfotek/article/view/87

Murdiansyah, I., Sudarma, M., \& Nurkholis, N. (2017). PENGARUH DIMENSI FRAUD DIAMOND TERHADAP PERILAKU KECURANGAN AKADEMIK (STUDI EMPIRIS PADA MAHASISWA MAGISTER AKUNTANSI UNIVERSITAS BRAWIJAYA). Jurnal Akuntansi Aktual, 4(2). 
Rahardja, U., \& Handayani, I. (2016). Penerapan SPB Online Menggunakan Rinfo Transformation Pada Bagian Pengadaan Perguruan Tinggi. CogITo Smart, 2(1), 28-41. Retrieved from http://cogito.unklab.ac.id/index.php/cogito/ article/view/15

Reni Hendrawati, \& Fatkhudin, A. (2015). Web Based Test Untuk Tryout Ujian Nasional Smp Nu Kajen Menggunakan Php, (1), 30-34.

Rosa Ariani Sukamto, M. S. (2013). Rekayasa Perangkat Lunak terstruktur dan berbasis Objek.

Sudaryati, S. (2016). Pengembangan Online Test System Untuk Siswa. Konferensi Nasional Penelitian Matematika Dan Pembelajarannya (KNPMP I), (Knpmp I), 686-694. Retrieved from

https://publikasiilmiah.ums.ac.id/bitstream /handle/11617/7012/74_38_Makalah Rev Sri Sudaryati.pdf? sequence=1\&isAllowed $=y$

Sulistiyono, R., Suyata, P., \& Rahayu, T. (2016). No Title. INVENTORY SURVAI UJIAN NASIONAL BAHASA INDONESIA BERBASIS KOMPUTER.

Suryana, A. (2015). Analisis Implementasi Model PACE pada Mata Kuliah Statistika Matematika. Jurnal Kajian Pendidikan Matematika (JKPM), 01(01), 91-105. 